\title{
Middle-school students' online information problem solving behaviors on the information retrieval interface
}

\author{
Yi-Fen Yeh, Ying-Shao Hsu, National Taiwan Normal University \\ Fu-Tai Chuang, Kaohsiung Municipal Rueisiang Senior High School \\ Fu-Kwun Hwang, National Taiwan Normal University
}

\begin{abstract}
With the near-overload of online information, it is necessary to equip our students with the skills necessary to deal with Information Problem Solving (IPS). This study also intended to help students develop major IPS strategies with the assistance of an instructor's scaffolding in a designed IPS course as well as on an Online Information Management (OIM) interface. Explicit strategies that students employed to organize information for final projects were identified and hierarchically leveled based on the cognitive complexity they required. Results from a correlation analysis showed a significantly positive relationship among students' project scores, IPS strategies (e.g. organizing information in a logical way), and explicit strategies (e.g. search terms), but no significant relationship involving implicit strategies. Further examinations showed the students with higher project scores had advanced IPS and implicit strategies, while those with intermediate or lower scores likely over- or under-estimated their utilisation of implicit strategies. That is, self-efficacy surveys can be discriminative instruments if students have good self-monitoring abilities. Another feature of the students with high proficiency on IPS was the use of full sentences when using search engines, which implied less demands for the exactitude in search term selection due to the advances of search engines.
\end{abstract}

\section{Background}

In this age of information explosion, technology allows for information to be accumulated and circulated at increasingly rapid rates. The ease of access to rich bodies of information has allowed online resources to become a major reserve for students conducting research for school projects, exploring new areas of knowledge on their own (Jones, 2002), or even seeking updates on entertainment-related information (Rose, Rose, \& Blodgett, 2009). However, intensive access to online information will not necessarily lead to well-honed information management skills (Lazonder \& Rouet, 2008). Considering the trend of teachers reinforcing their students' use of the internet for research and information gathering (Becker, 1999), this study attempts to identify student behaviours when solving online information problems developed from an Information Problem Solving (IPS) curriculum. We would also like to analyse the records of search terms used and websites visited which were recorded in the OIM interface, as well as the quality of information presented in students' final projects.

\section{Information retrieval vs. Information problem-solving}

According to the Information Processing Model (Gagne, Yekovich, \& Yekovich, 1993), human brains process external stimuli through a process of initial information reception, selective perception of key information, automatic information processing through both working memory and long-term memory, information retrieval and, finally, a creative generation of responses. By analyzing search behaviours through screenshot records and interviews, early researchers identified the major stages and strategies that information seekers employ when searching for information (e.g. Ackerman \& Karen, 2005; Ellis, 1989; 1993; Kim, Hannafin, \& Bryan, 2007; Kuhlthau, 1993; Wallace, 1997). Common online information browsing patterns include first time/revisit, page reload, hub-and-spoke (Tauscher \& Greenberg, 1997), breadth-first/depth-first (Jenkins, Corritore, \& Wiedenbeck, 2003; Thatcher, 2006, 2008), topdown/bottom-up (Navarro-Prieto, Scaife, \& Rogers, 1999), linear/nonlinear (Qiu, 1993), etc. Both the nature of tasks (i.e. task complexity, problem structure) and the competence of the information seekers (i.e. cognitive structure, prior knowledge) may determine the quality of their information retrieval (Sharit, Hernández, Czaja, \& Pirolli, 2008). After a variety of strategies and factors that contribute to the overall information search process were identified (Hsie-Yee, 2001; Jansen \& Pooch, 2001), researchers in the past decade switched their attention to Information Problem Solving (IPS) (Brand-Gruwell, Wopereis, \& 
Vermetten, 2005), with a converging focus on developing students' information problem solving (IPS) abilities.

IPS abilities include the ability not only to seek information, but also to organise and manage the information obtained. Based on the Big6 model (Eisenberg \& Berkowitz, 1990, 1992; Eisenberg, Berkowitz, Darrow \& Spitzer, 2000), Brand-Gruwell, et al. (2005) proposed the IPS model, including five major strategies that experts and novices use when completing IPS tasks (i.e. defining the information problem, searching for the information, scanning for the information, processing the information, and organising and presenting the information) in conjunction with their regulatory skills (i.e. orientation, monitoring, steering, and testing). Brand-Gruwell, Wopereis and Walraven (2009) further elaborated upon this model by adding reading skills, evaluation skills, and computer skills as conditional skills, all of which are also skills required for Web literacy (Kuiper, Volman, \& Terwel, 2008). Critical reading is also important for effective online information searching and management, since it can help information seekers shape the scope of the search and the information collected in the five-stage comprehension process (Mokhtari, Kymes, \& Edwards, 2009). With the IPS model, we know not only the cognitive capacity that information seekers need to acquire but also various instructional ideas information educators can use to assist students in honing their research strategies at various stages of the process.

\section{Strategies related to information problem solving}

Some stages in IPS can be difficult for students and warrant further exploration. In a review study of IPS studies (Walraven, Brand-Gruwel, \& Boshuizen, 2008), prior knowledge activation and information evaluation are critical contributors to the quality of information seekers' search term specifications and information organisation, but they are also difficult skills for teenage learners to develop in the first through third IPS stages. Prior knowledge prepares students to judge the relevancy of information and make decisions regarding the information they find (Foster, 2005; Kuhlthau, 1993; Raban, 2007), and prior experiences with hypermedia may sustain users' orientation toward internet searching (Hill \& Hannafin, 1997; Liang \& Tsai, 2009; Liaw \& Huang, 2006; Marchionini, 1995; Tabatabai \& Shore, 2005). Lacking a good understanding of the topic limits the scope and the depth of the search results, and even the quality of any informational argument revision (Belkin, 2000; Butcher \& Summer, 2011; Chen, Fan, \& Macredie, 2006). In that way, researchers found that keeping reflective notes while searching information enhanced students' information evaluation abilities, especially when students were engaged to think aloud through the evaluation criteria (Gerjets, Kammerer, \& Werner, 2011; Walraven, BrandGruwel \& Boshuizen, 2009) or to transfer their complex cognitive skills through highroad (i.e. abstract steps in the process) or rich representation programs (i.e. conceptual maps) (Walraven, Brand-Gruwel, \& Boshuizen, 2010, 2013). Very few studies have been conducted to scrutinise the last two stages of IPS (i.e. information processing, information organisation and presentation) (Walraven, et al., 2008). According to the original framework of IPS, these two stages require students to perform "the synthesis of relevant information into cogent, productive uses" (Brand-Gruwel et al., 2005, p. 491). Argument or report writing can be good practises, since they require students not only to collect relevant information but also to weave and rewrite the information with coherent logic and a global understanding of this information. In that way, analyzing students' behaviors on different search term usages, website selections, and information rewriting shall reveal the ways in which students solve information problems at the last two stages.

There are also regulatory skills that sustain cognitive skills throughout the five stages of the IPS model. According to Schraw (1998), learners' metacognition is composed of: 1. knowledge about cognition, and 2. regulation of cognition (i.e. planning, monitoring, and evaluation). The extensive information available online requires information seekers to make a search plan first, and then monitor and steer through that information, as well as evaluate if their plan is properly conceived or if it needs adjustment (BrandGruwell et al., 2005; Hill, 1999). Information seekers' epistemic beliefs also influence how they solve information problems and construct related knowledge (Mason, Ariasi, \& Boldrin, 2011). Tsai and Tsai (2003) identified a total of eight self-regulatory strategies that college students employ in online information searches from the data of their think-aloud and searching behaviors. They are strategies in the domains of the behavioural (i.e. control, disorientation), procedural (i.e. trial and error, problem solving), and metacognition (purposeful thinking, selection of main ideas, evaluation). Tsai, Hsu, and Tsai (2012) deemed these metacognitive or self-reflective strategies as implicit strategies, while the observable or quantifiable behaviours that can be recorded by screen capture software were termed explicit strategies 
(e.g. search term entering, webpage exploration). Their studies found the disconnects between explicit and implicit strategies (Tabatabai \& Shore, 2005; Tsai et al., 2012), but the reasons for this incompatibility require further investigation.

\section{Online information management (OIM) interface}

Different types of user-friendly interfaces have been developed to optimize the advantages of online information gathering (e.g. rich volume of information, easy access, etc.); however, it is also important to minimize the burden created by the overflow of online information and vast complexity of web connections (Nielsen, 1994; Tauscher \& Greenberg, 1997). Knowledge Integration Environment (KIE) projects and Web-based Integrated Science Environments (WISE) are built-in functions of electronic notepads that allow students to "write down" their reflections or take notes on what they read (Bell, Davis, \& Linn, 1995). Besides notepads, the nStudy browser also encourages its users to tag important information in a web page, as well as to annotate quotes and bookmarks attached to web pages (Winne \& Hadwin, 2013). Functions like displaying the graphical, visual representations from a user's collected information and the websites they visited are also designed to help users recall the information they obtain from their browsing (Levin \& Kauwell, 1999). These designs enable users to organise collected information and their thinking through reflective writing and conceptual maps, which are deemed as effective instructional strategies to help students complete their IPS tasks (de Vries, Van der Meij, Lazonder, 2008; Gerjets, et al., 2011; Walraven et al., 2010, 2013). Additionally, students' search process can be recorded as search portfolios. Teachers can use the Meta-Analyser to know the frequency and duration of the websites students browse, as well as the number of search terms they use (Hwang, Tsai, Tsai, \& Tseng, 2008). Although functions such as bookmarking useful websites help students to sort out irrelevant information resources, an interface where users can collect and edit information would help decrease the hassles students experience with information management, as well as enable teachers to examine students' progress in their information management.

\section{Research Questions}

Faced with the previously mentioned urgent needs of students regarding their ability to properly manage the wealth of information provided by the internet, IPS tasks should seek to develop and refine students' information organisation and presentation abilities by contextualising those abilities within the greater body of rich online information. We are interested in developing students' information problem solving strategies through an IPS course and an OIM interface. Our preliminary research questions / research attempts are proposed, as follows:

1. What strategies did students use to help them complete the IPS tasks for their project works?

2. How are the strategies, explicit and implicit, used by students correlated?

3. How did the IPS course and the OIM interface develop students' IPS strategies?

\section{Method}

Researchers in this study designed an IPS course and an OIM interface geared toward assisting students' information problem solving abilities. Students' search strategies were identified and cross-referenced with the explicit behaviours they demonstrated when interacting with the OIM interface, and with their final projects. Their implicit search behaviours were collected and analyzed through their performances on self-reported efficacy surveys.

\section{Participants}

The participants were 12 male and 16 female students in the seventh grade from a school located in a suburban area in southern Taiwan. They took the Online Information Searching Strategy Inventory (OISSI) (Liang \& Tsai, 2009) before and after the one-year IPS course $(\alpha=0.91)$.

\section{IPS Course}

We developed an IPS course by following the framework of IPS (Brand-Gruwel et al., 2005), as shown in Table 1. Five thematic tasks within science or computer-related subjects were sequentially offered in a one hour, weekly course entitled "Computer Skills," which lasted for 25 weeks within two consecutive 
semesters. Taken as a complete IPS task, each unit required the instructor to begin with defining the information problem, then proceed to searching for the information, scanning the information, processing the information, and finally to organising and presenting the information. Under the scaffolding theory that lends itself to a gradual release and transfer of responsibilities (Stone, 1998), the instructor first offers explicit instructions designed to lead students to perform searches in a methodical, step-by-step (modelling) approach, then guides students to perform further searches with fewer moments of support (or coaching); finally, the instructor encourages the students to run searches on their own while providing only minimal support (fading). Besides developing students' IPS abilities, the course is also designed to enhance students' understanding of selected concepts regarding computers and science (e.g. computer composition, reflection and refraction) through knowledge acquisition, knowledge transformation, and knowledge construction (Gagne et al., 1993; Liaw \& Huang, 2006). Repetitive cycles of information searching, scanning, and processing were conducted in each unit, until the instructor and the students were satisfied with the search results.

\section{Online information management (OIM) interface}

This study was designed to involve a multi-functional interface the students used throughout five units. Graphical organisers of search terms and search results (see Figure 1) as well as a note-taking pad (see Figure 2) were implemented into the interface in order to assist the students in monitoring their search process and making their edits and reflective notes on important information they encountered:

- Searching - Students can access Google directly via the OIM interface;

- Website Summary - The OIM interface was merged with Google's search system and displays the search results Google provides (i.e. related website links, website summarises). Students could click on the website links directly from the OIM interface. New screens popped out in an effort to avoid conditions such as the original screen being closed or the information disappearing.

- Search Record - The OIM interface keeps tracks of the search terms students use when searching, and the websites they visit (displayed as tree diagrams). Both the frequency of the search terms they use and the moment they visit the websites are also provided beside each record.

- Note-taking - Students can organize information through "copying-dragging-pasting" the target information or writing notes in the same interface.

\section{Data analysis}

Students' learning progress were evaluated by their self-reported online information searching efficacy (Liang \& Tsai, 2009) and the actual strategies they utilized to manage their collected information. We collected data from students' search terms and website search history recorded in the OIM interface, their assignments and worksheets, and their final projects for units 4 and 5. Two experienced teachers who had at least 20 years of teaching experience in the subject of computers were involved in the construction of the coding scheme for the IPS strategies the students utilized. After coding the students' search behaviours separately, the two teachers reviewed the students' data again and discussed their findings in order to reach an agreement regarding the patterns of student search behaviours. A total of six main categories of students' search behaviours were identified (Table 2). The inter-rater reliability between the two teachers was 0.94 .

Rubrics were also made for scoring how these students utilized strategies to manage and present the collected information in the final projects for unit 4 (self-selected topics) and unit 5 (teacher-defined topics) (see Table 3). Zero to two points were given in each category of information variety, completeness, accuracy, organisation, and presentation (Table 3). In order to score the information the students finally included in their project works in an unbiased way, the two teachers also checked the content of the websites that students left in the records of the OIM interface. Taking the item "information organisation" as an example, student 6 earned two points for his self-selected topic of "global warming", since he collected information on the factors, possible effects, and preparations for global warming, presented the information as an outline in the beginning of the project he submitted, and rewrote the information in order to make it more coherently connected. For the self-selected topic "the impacts of a typhoon," student 10 received only one point since he outlined the information he was going to present (i.e. what is a typhoon? what disaster would typhoons bring? how do we prepare for typhoons and decrease the possible impacts?), without some other common disasters provided as examples. No point was awarded 
for student 20 in unit 5, because the ample body of information he collected was only presented according to sub-topics, without any content rewriting.

Table 1

Design of the IPS Course

\begin{tabular}{|c|c|c|}
\hline & Unit 1: What is openoffice? (4hrs) & Unit 2: Computer composition (5 hrs) \\
\hline $\begin{array}{l}\text { Define the } \\
\text { Info. Problem }\end{array}$ & $\begin{array}{l}\text { - Recall student knowledge of word } \\
\text { processing systems; } \\
\text { - Introduce the search task; }\end{array}$ & $\begin{array}{l}\text { - Recall student knowledge of computer } \\
\text { composition; } \\
\text { - Introduce the search task; }\end{array}$ \\
\hline Search Info. & $\begin{array}{l}\text { - Learn how to use search engines; } \\
\text { - Search the term openoffice; } \\
\text { - Read the website summary of the } \\
\text { search results; }\end{array}$ & $\begin{array}{l}\text { - Learn how to use the OIM interface; } \\
\text { Enter related terms; } \\
\text { - Judge search results from the website } \\
\text { summary; }\end{array}$ \\
\hline Scan Info. & $\begin{array}{l}\text { - Introduce the structure of websites; } \\
\text { - Teach basic knowledge of URL (e.g. } \\
\text { acronyms for ".com",".edu"); }\end{array}$ & $\begin{array}{l}\text { - Find out which websites contain the } \\
\text { intended info; } \\
\text { - Evaluate the validity of website info; }\end{array}$ \\
\hline Process Info. & $\begin{array}{l}\text { - Select the website that best describes } \\
\text { openoffice according to the website } \\
\text { summary and website info; }\end{array}$ & $\begin{array}{l}\text { - Understand the concepts of computer } \\
\text { composition from different websites; } \\
\text { - Copy-drag-paste info. in OIM interface; }\end{array}$ \\
\hline $\begin{array}{l}\text { Organize \& } \\
\text { Present Info. }\end{array}$ & $\begin{array}{l}\text { - Demonstrate what info should be } \\
\text { collected }\end{array}$ & $\begin{array}{l}\text { - Summarize the collected info on } \\
\text { computer composition }\end{array}$ \\
\hline $\begin{array}{l}\text { Features of } \\
\text { OIM Interface }\end{array}$ & Searching & $\begin{array}{l}\text { Searching; Note-taking; searching history } \\
\text { of websites and search terms }\end{array}$ \\
\hline
\end{tabular}

Unit 3: Reflection and refraction

Unit 4 \& 5: Make a presentation $(12 \mathrm{hrs})$

(4hrs)

\begin{tabular}{|c|c|c|}
\hline $\begin{array}{l}\text { Define the } \\
\text { Info. Problem }\end{array}$ & $\begin{array}{l}\text { - Guide students to formulate } \\
\text { questions based on their prior } \\
\text { knowledge; } \\
\text { - Set search goals with students; }\end{array}$ & $\begin{array}{l}\text { - Formulate questions for searches; } \\
\text { - Make plans for searching complex } \\
\text { scientific concepts; }\end{array}$ \\
\hline Search Info. & $\begin{array}{l}\text { - Guide students to select different } \\
\text { related search terms; } \\
\text { - Learn how to search for pictures; } \\
\text { - Identify useful online info; }\end{array}$ & $\begin{array}{l}\text { - Initiate searches with self-selected, } \\
\text { relevant terms; } \\
\text { - Read through the website summary to } \\
\text { catch important info; }\end{array}$ \\
\hline Scan Info. & $\begin{array}{l}\text { - Find the pictures and content that } \\
\text { best describe reflection and } \\
\text { refraction; } \\
\text { - Regularly remind students of the } \\
\text { purpose of their searches; }\end{array}$ & $\begin{array}{l}\text { - Identify the websites that provide } \\
\text { authoritative info; } \\
\text { - Modify search plans by considering what } \\
\text { info is still lacking; }\end{array}$ \\
\hline Process Info. & $\begin{array}{l}\text { - Generate criteria for judging the } \\
\text { accuracy of online info; } \\
\text { - Organize relevant info regarding } \\
\text { reflection and refraction; }\end{array}$ & $\begin{array}{l}\text { - Evaluate the accuracy of the info; } \\
\text { - Develop concept maps of the search } \\
\text { terms; } \\
\text { - Conduct further searches if necessary; }\end{array}$ \\
\hline $\begin{array}{l}\text { Organize \& } \\
\text { Present Info. }\end{array}$ & $\begin{array}{l}\text { - Use the collected online info to } \\
\text { complete worksheets }\end{array}$ & $\begin{array}{l}\text { - Outline useful info; } \\
\text { - Organize info into projects }\end{array}$ \\
\hline $\begin{array}{l}\text { Features of } \\
\text { OIM Interface }\end{array}$ & $\begin{array}{l}\text { Searching; Note-taking; website and } \\
\text { search term records }\end{array}$ & $\begin{array}{l}\text { Searching; Note-taking; website and } \\
\text { search term records }\end{array}$ \\
\hline
\end{tabular}




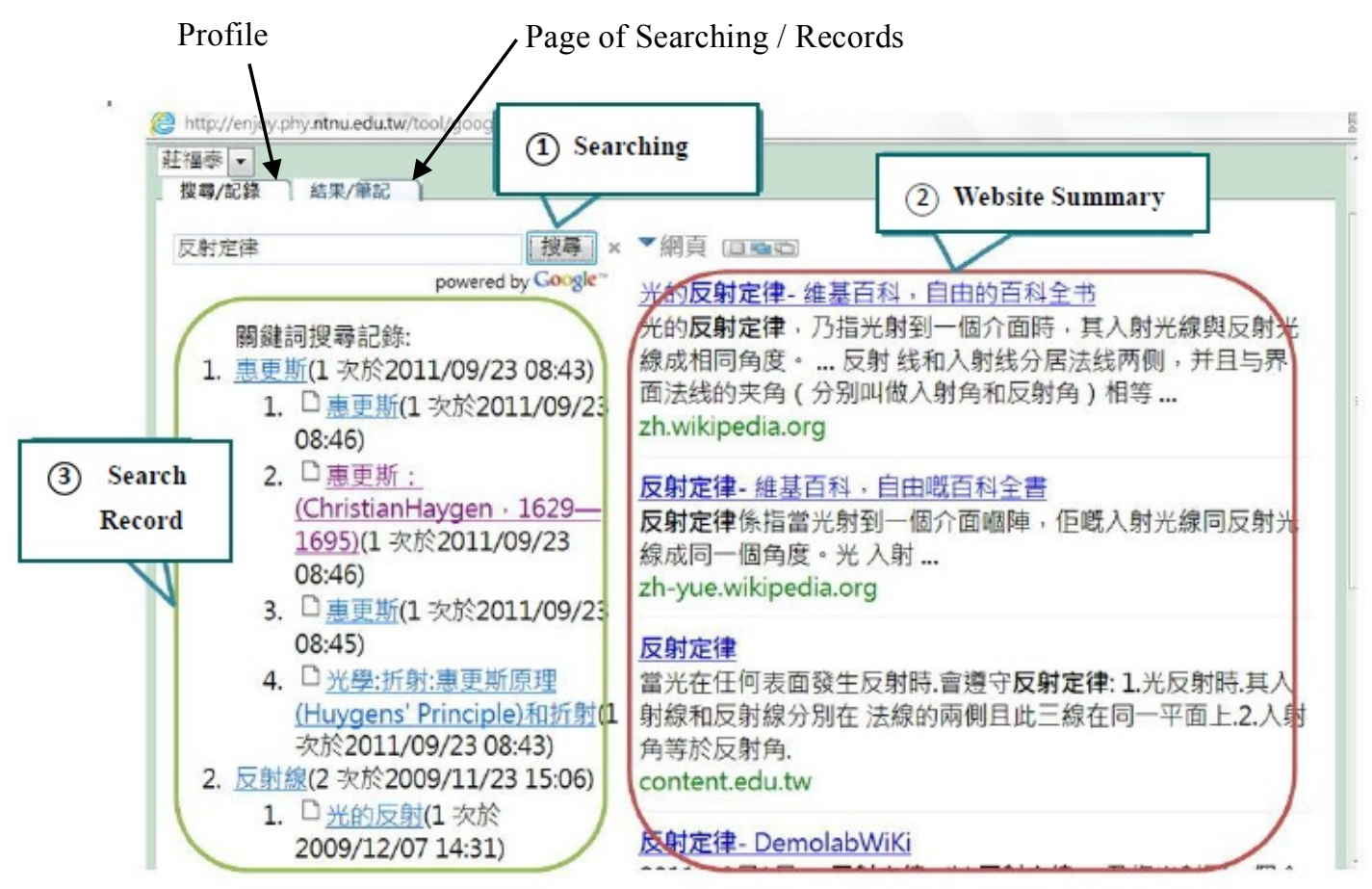

Figure 1. The interface of information searching and recording

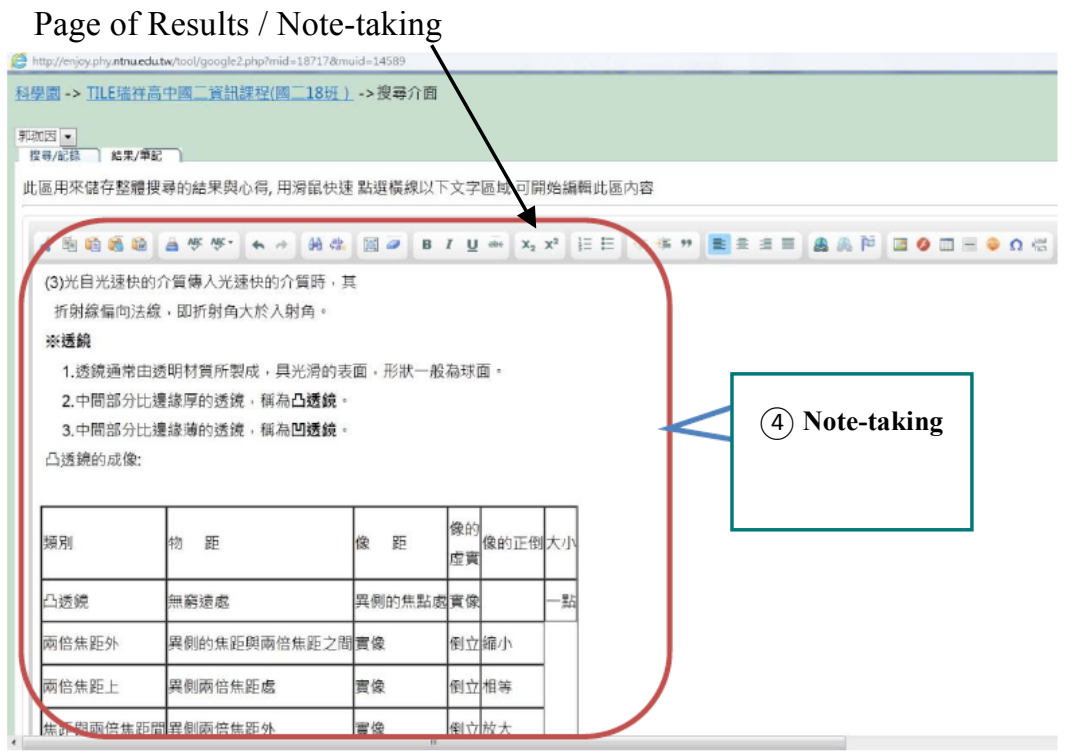

Figure 2. The interface of note-taking 
Table 2

Coding scheme for the IPS strategies

\begin{tabular}{|c|c|c|}
\hline Codes & IPS strategies & $\begin{array}{l}\text { Search behaviours identified from students' } \\
\text { searching records or projects }\end{array}$ \\
\hline $\mathrm{A}$ & $\begin{array}{l}\text { Initiating searches with one } \\
\text { relevant search term }\end{array}$ & Records of search terms related to the topics \\
\hline B & $\begin{array}{l}\text { Choosing websites based on their } \\
\text { summaries }\end{array}$ & $\begin{array}{l}\text { Records of multiple websites relevant to the topics } \\
\text { being searched }\end{array}$ \\
\hline $\mathrm{C}$ & $\begin{array}{l}\text { Collecting textual or pictorial } \\
\text { information }\end{array}$ & $\begin{array}{l}\text { Records of relevant information in text or diagrams } \\
\text { being collected or used }\end{array}$ \\
\hline D & $\begin{array}{l}\text { Searching for information with } \\
\text { multiple search terms }\end{array}$ & $\begin{array}{l}\text { Records of using multiple relevant terms to search for } \\
\text { information on the same topic }\end{array}$ \\
\hline $\mathrm{E}$ & $\begin{array}{l}\text { Answering questions with } \\
\text { collected information }\end{array}$ & $\begin{array}{l}\text { Correct answers to the information problem-solving } \\
\text { questions in the worksheets }\end{array}$ \\
\hline $\mathrm{F}$ & $\begin{array}{l}\text { Organising collected information } \\
\text { in a logical way }\end{array}$ & $\begin{array}{l}\text { Logical information organisation is defined by the } \\
\text { criteria of: } \\
\text { - topic-focused presentation; } \\
\text { - effective outlines for paragraph or slide content; } \\
\text { - at least three paragraphs; and ideas or paragraphs } \\
\text { woven into a coherent flow }\end{array}$ \\
\hline
\end{tabular}

Table 3

Rubrics for students' projects

\begin{tabular}{llll}
\hline Criteria & \multicolumn{1}{c}{0} & \multicolumn{1}{c}{1} & \multicolumn{1}{c}{2} \\
\hline $\begin{array}{l}\text { Variety of } \\
\text { Information }\end{array}$ & Single resource & Two resources & Over three resources \\
$\begin{array}{l}\text { Completeness } \\
\text { of Information }\end{array}$ & $\begin{array}{l}\text { Incomplete information } \\
\text { about the topic }\end{array}$ & $\begin{array}{l}\text { Partial information about } \\
\text { the topic was clear }\end{array}$ & Complete information \\
$\begin{array}{l}\text { Accuracy of } \\
\text { Information }\end{array}$ & $\begin{array}{l}\text { Information from folklore, } \\
\text { stories, or forums }\end{array}$ & $\begin{array}{l}\text { Information from personal } \\
\text { blogs or daily news clips }\end{array}$ & $\begin{array}{l}\text { Information from academic } \\
\text { or government authorities }\end{array}$ \\
$\begin{array}{l}\text { Information } \\
\text { Presentation }\end{array}$ & No tables or figures in use & $\begin{array}{l}\text { Inappropriate or irrelevant } \\
\text { tables or figures in use }\end{array}$ & $\begin{array}{l}\text { Appropriate uses of tables } \\
\text { and figures }\end{array}$ \\
$\begin{array}{l}\text { Information } \\
\text { Organisation }\end{array}$ & $\begin{array}{l}\text { Direct quotes without } \\
\text { information organisation }\end{array}$ & $\begin{array}{l}\text { Partial information being } \\
\text { organised or paraphrased }\end{array}$ & $\begin{array}{l}\text { Logical information } \\
\text { organisation and } \\
\text { meaningful paraphrases }\end{array}$ \\
\hline
\end{tabular}

\section{Results}

These students' performances in online information management were cross-referenced through their self-efficacy scores, actual performances in information management, and the final reports they submitted. Major patterns of students' search behaviours are also identified and leveled based on the complexity their cognitive abilities required. An alignment of their performances on implicit and explicit strategies as well as the uses of search terms and websites are also analysed and discussed.

\section{Implicit strategies}

In order to investigate whether the IPS course enhanced their online information management efficacy, non-parametric tests were used to analyse students' pre- and post-scores that they performed in OISSI. Significant improvements were found in students' overall scores $(z=3.05, p=.02)$ (see Table 4). The difference between the pre-test $(M=113.79, S D=15.06)$ and the post-test $(M=123.82, S D=16.96)$ demonstrates a medium effect size (Cohen's $d=0.63$ ). However, such an improvement was not consistent for each of the IPS strategies. Significant score improvements were found in the categories of "evaluation" 
$(z=2.75, p=.06)$, "purposeful thinking" $(z=2.11, p=.04)$, "select main ideas" $(z=2.43, p=.02)$, and "control" $(z=2.95, p<.01)$.

Table 4

Implicit strategy performances on OISSI $(N=28)$

\begin{tabular}{|c|c|c|c|c|c|c|c|c|c|}
\hline Implicit & & & e-test & & & $\mathrm{Po}$ & st-test & & \\
\hline & Min. & Max. & $M$ & $S D$ & Min. & Max. & $M$ & $S D$ & $z$ \\
\hline Disorientation & 4 & 24 & 17.57 & 6.07 & 7 & 24 & 18.61 & 5.19 & 1.20 \\
\hline Evaluation & 4 & 24 & 15.93 & 4.52 & 10 & 24 & 18.54 & 4.44 & $2.75 * * *$ \\
\hline $\begin{array}{l}\text { Purposeful } \\
\text { Thinking }\end{array}$ & 5 & 24 & 19.39 & 3.80 & 11 & 24 & 20.64 & 3.14 & $2.11 * *$ \\
\hline Trial \& Error & 9 & 18 & 15.07 & 2.76 & 9 & 18 & 15.82 & 2.28 & 1.41 \\
\hline $\begin{array}{l}\text { Select Main } \\
\text { Ideas }\end{array}$ & 3 & 18 & 13.43 & 3.31 & 7 & 18 & 14.89 & 2.59 & $2.43 * *$ \\
\hline Control & 12 & 24 & 18.64 & 3.13 & 13 & 24 & 20.86 & 2.73 & $2.95 * * *$ \\
\hline $\begin{array}{l}\text { Problem } \\
\text { Solving }\end{array}$ & 9 & 18 & 13.75 & 2.68 & 5 & 18 & 14.46 & 3.26 & 1.65 \\
\hline Overall Scores & 72 & 138 & 113.79 & 15.06 & 92 & 150 & 123.82 & 16.96 & $3.05 * * *$ \\
\hline
\end{tabular}

\section{IPS strategies}

Through further examination of individual sets of search profiles and their associated project work, students' search behaviours can be synthesized into six strategies at three proficiency levels, according to the cognitive complexity these strategies require (see Figure 3). The number noted within each box is the number of students who demonstrated the indicated ability, while the numbers between the boxes are the numbers of students who performed both of the strategies to which the lines connect. We found students who demonstrated the highest level strategies (F, E) also performed the strategy at the inter-mediate level (D); those who demonstrated strategy D demonstrated all of the strategies at the basic level (A, B and C). In other words, the six students who demonstrated the highest level (F) strategy also demonstrated all of the strategies at the lower levels.

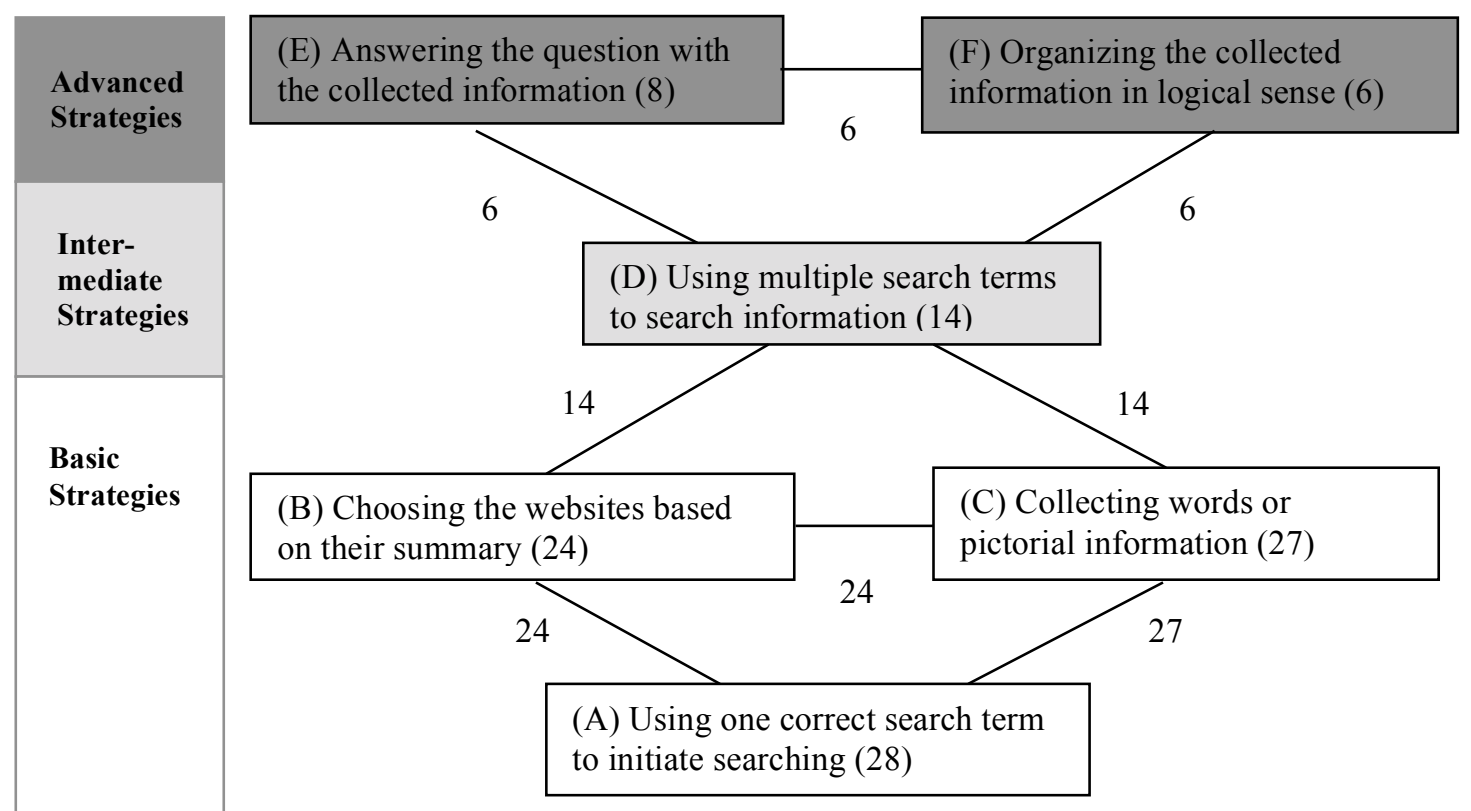

Figure 3.IPS strategies at different proficiency levels 
Student 10, for example, demonstrated all six strategies throughout his information search process. He was able to use multiple appropriate search terms (e.g. hard disks, keyboards, and computer mice) to initiate his searches for unit 2 (strategies A \& D). After entering the search term "reflection of light" in unit 3 , he first browsed the website summary of eight related websites that the search engines displayed (strategy B), and then offered adequate responses to the questions regarding the reflection and refraction of light that were provided in worksheets (strategy E). For the self-selected topic (typhoon), he used sentences as search terms to initiate his searches, such as "what preparation do we need to do for typhoon strikes?" After visiting several websites that contained information and pictures of typhoons, he coherently synthesized and organised the definition of typhoons, the disasters caused by typhoons, various cases of typhoons, and some possible typhoon preparation measures (strategies C \& F).

\section{Patterns of search terms and familiarity of topics (explicit strategies)}

We also analysed the students' behaviours regarding search terms and website selection, according to their search records. Three different types of keywords were found in the students' search terms. The search terms were either nouns (e.g. typhoon, reflection), phrases (e.g. pictures of the melting North Pole; the structure of a computer hard drive), or complete sentences (e.g. how do we prepare ourselves for a typhoon?; how does global warming influence the animals in a polar region?). Table 5 lists the frequency of search term utilisation and the websites being visited when they searched for information on selfselected and teacher-defined topics. More search terms and websites were used for the self-selected topics (1.68 websites, on average) than for the teacher-defined topic of earthquakes (1.21 websites, on average).

Table 5

Numbers of search terms used and websites visited

\begin{tabular}{lcc}
\hline Topics & Search Terms & Websites \\
\hline Self-selected topics (unit 4) & 62 & 104 \\
Teacher-defined topics (unit 5) & 48 & 58 \\
\hline
\end{tabular}

Students' selections of search terms and websites were found to be dependent on their familiarity with the project topics. Student 7 initiated her search by entering "the impacts of floods", "the impacts that floods bring to human beings", "what are the factors for floods?" etc. She also browsed five web pages and read one twice, which contained rich information about floods. However, she merely used phrases such as "earthquake 921" and scanned only four websites. Her project for unit 4 demonstrated her ability to collect and organise relevant information in text and diagrams, but not by information rewriting; her project for unit 5 lacked complete information and an outline.

\section{Correlations of IPS performances}

The quality of the projects that the students submitted also acted as an indicator of the effectiveness of the IPS strategies they used. After scoring with the rubrics listed in Table 3, the students' final projects for units 4 and 5 were evaluated with scores ranging from zero to 10 . The students whose scores were one $S D$ higher and one $S D$ lower than the average scores were grouped into the group with higher project scores $($ H.P., $\mathrm{n}=5$ ) and the group with lower project scores (L.P., $\mathrm{n}=4)$ respectively, while the other students were grouped into the group with intermediate project scores (I.P., $n=18$ ). Table 6 lists the number of students who demonstrated different proficiency levels in explicit strategies and who used different formats of search terms within each group of similar project scores. A preliminary trend was that the students with higher project scores used more advanced IPS strategies and engaged more complex search terms (i.e. phrases, sentences). Four out of six students who had higher project scores used sentences in their searches, whereas very few of the students whose scores were in group I.P. or group L.P. used sentences and phrases. The quantity and format of the search terms used seemed to vary according to the students' search behaviours and the scores they received on their final projects. 
Table 6

Relationships between IPS strategies, explicit strategies and project scores

\begin{tabular}{lccc}
\hline & \multicolumn{3}{c}{ Project Scores } \\
\cline { 2 - 4 } & H.P. & I.P. & L.P. \\
& $(M=13.8, S D=1.30)$ & $(M=7.44, S D=1.62)$ & $(M=2.5, S D=1.91)$ \\
\hline IPS Strategies & 0 & 6 & 4 \\
Basic & 0 & 12 & 0 \\
Inter-mediate & 6 & 0 & 0 \\
Advanced & & & 4 \\
Formats of Search Terms & 0 & 11 & 0 \\
Single word & 2 & 5 & 0 \\
Phrases & 4 & 2 & 0 \\
Sentences & & & \\
\hline
\end{tabular}

In order to understand how different strategies contribute to the proficiency of students' IPS, we made correlational analyses among project scores, implicit strategies, IPS strategies, and explicit strategies (i.e. frequency and formats of search terms, numbers of visited websites). In contrast to the high correlations among project scores, the proficiency levels of IPS strategies, and explicit strategies (Table 7), the insignificant correlation found between the scores of implicit strategies to other strategies somewhat echoed the findings of Tsai et al. (2012).

Table 7

Correlations among implicit strategies and explicit strategies

\begin{tabular}{lccccc}
\hline Performances & $\begin{array}{c}\text { Project } \\
\text { scores }\end{array}$ & $\begin{array}{c}\text { Implicit } \\
\text { strategies }\end{array}$ & $\begin{array}{c}\text { IPS } \\
\text { strategies }\end{array}$ & $\begin{array}{c}\text { Number of } \\
\text { search terms }\end{array}$ & $\begin{array}{c}\text { Formats of } \\
\text { search terms }\end{array}$ \\
\hline Implicit strategies & .10 & & & & \\
IPS strategies & $.83^{*}$ & .22 & & & \\
Numbers of search terms & $.71^{*}$ & .05 & $.66^{*}$ & $.60^{*}$ & $.58^{*}$ \\
Formats of search terms & $.65^{*}$ & -.19 & .05 & $.66^{*}$ & \\
Numbers of visited websites & .70 & .05 & $.68^{*}$ & & \\
\hline
\end{tabular}

* means significance at 0.001 level.

Students' scores on implicit strategies were further analyzed to investigate possible reasons for the insignificant correlations between implicit strategies to other strategies. We scattered the average pre-test and post-test scores from the groups with advanced, intermediate, and basic IPS strategies in Figure 4. The group with advanced IPS strategies improved most of their implicit strategy scores, followed by the groups with intermediate or basic proficiency levels of explicit strategies. The group with basic IPS strategies had negative score differences between tests on "evaluation", "trial \& error", and "select main ideas," which were suspected to be linked to the over-ratings of their strategy utilisation on the pre-tests. In other words, it was likely that the IPS course helped these students gain a better understanding of the self-efficacy items, more accurate self-monitoring skills, or/and better mastering of strategies in procedural domain and metacognitive domain (Tsai \& Tsai, 2003; Liang \& Tsai, 2009). However, it should be noted that the differences among the three groups mentioned above were not statistically significant $(\alpha=0.05)$. Only the group with advanced IPS strategies had consistently higher implicit strategy scores and project scores $(r=.94, \mathrm{p}<.05)$. All of these findings suggest that users who demonstrate good search behaviours usually have better implicit strategies and self-monitoring abilities, while users who do not develop good search strategies may need structured instruction to develop their implicit strategies and more practise to evolve their implicit strategies into explicit strategies. 


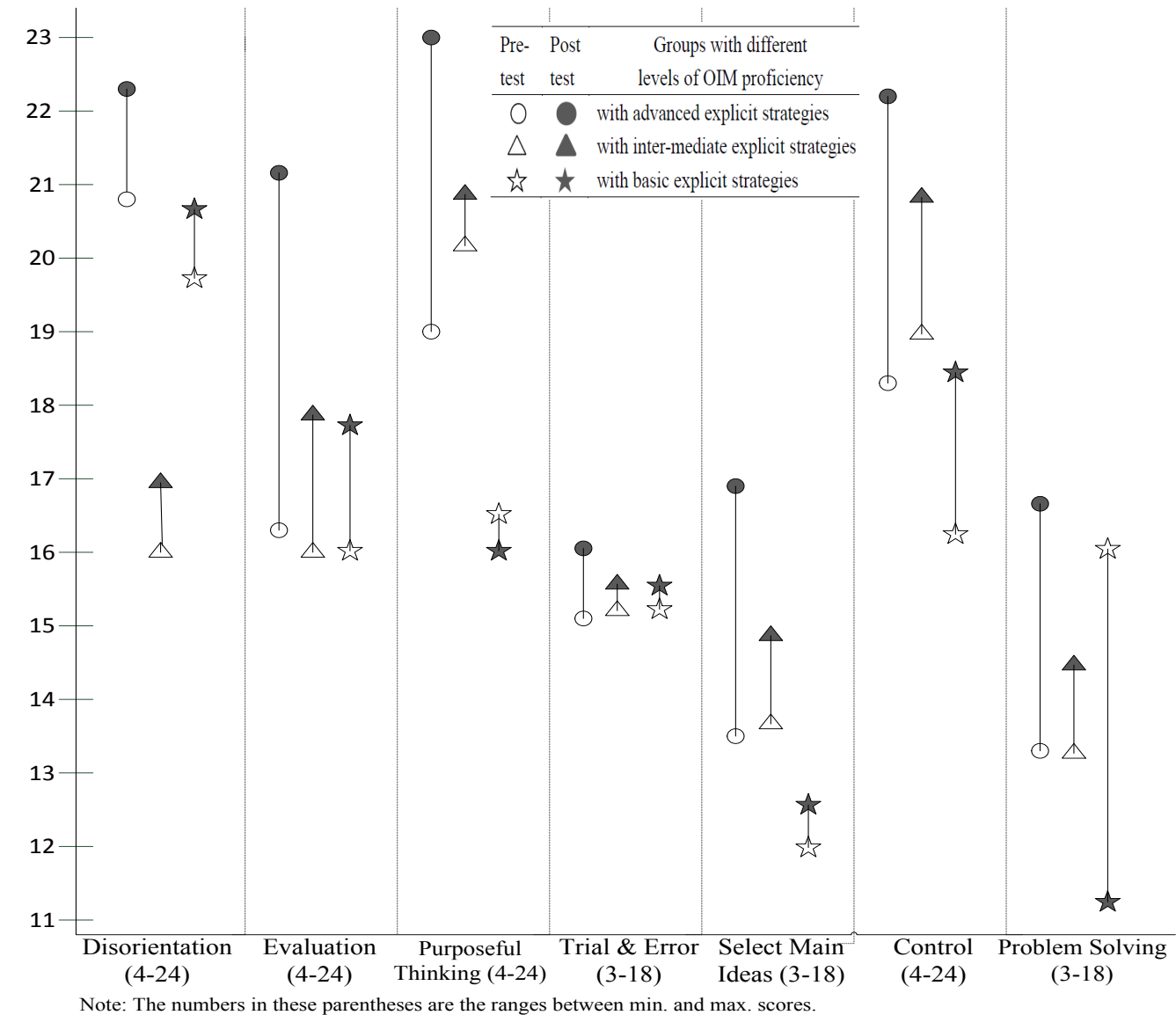

Figure 4. Score comparisons of implicit and IPS strategies

\section{Design features of the OIM interface}

Based on the informal user feedback when operating the OIM interface, the students did not report experiencing any difficulties with the OIM interface because it was similar to most of the common search engines. They felt that the search term and website recording functions were helpful to their information search. From the students' search records, almost all of the students (27 out of 28) used the OIM interface to conduct their searches. However, although they felt that the copy-drag-paste function was intuitive, there were still certain functions they felt were difficult to master or that needed to be improved. Due to the unfamiliarity with the icons in the tool bar, they reported that it was easy to forget to hit the "save" button that was located at the bottom of the interface. Saving all of the collected information on the same screen, which was designed to help students organise, actually ended up making the collected information difficult to read and organise. Also, not all of the website pictures could be recorded completely in the OIM interface.

\section{Discussion}

In this study, after taking the IPS course and practising searches on the OIM interface, the middle school students rated themselves with significantly higher scores on their use of "evaluation", "purposeful thinking" and "select main ideas", all of which are defined to be within the meta-cognitive domain (Tsai \& Tsai, 2003). The significant score improvements in these categories can likely be attributed to classroom elements such as an instructor's explicit guidance given in an effort to help students master the OIM interface (i.e. control), consistent reminders for students to monitor whether the terms being searched and the information being collected are properly aligned to the intended search topics (i.e. purposeful thinking), and scaffolding assistance geared toward modelling students' IPS strategies and coaching them to think about the collected information (i.e. select main ideas, evaluation). However, such continuous encouragement and scaffolding hints are probably the main reason for the insignificant level 
of improvement on "disorientation" and "problem solving", since they decrease the opportunities for users to experience difficulties on their own, and deal with the frustrations of independent online searching. Lastly, since the students in this study were encouraged to search information only on the OIM interface, it is not surprising to see insignificant improvements in the students' attitudes regarding using different search engines ("trial \& error").

The relevance of collected information was highly determined by the selection of search terms entered into the search engine and the information seekers' knowledge of the subject. Both single search terms and complete phrases are commonly used in most search engines (Wallace et al., 2000) and the majority of searches are not processed with Boolean operators (Mahoui \& Cunningham, 2000). In other words, information seekers are likely to use less complex search terms. By investigating the search term records left in the OIM interface, we found that 1 . some students used sentences to initiate searches, and 2. those students who used sentences or phrases were the students with higher, or at least mediocre, IPS abilities (according to their project scores, IPS strategies). Such findings were surprising, especially in cases where the instructor of the IPS course never initiated searches with search terms in front of them. We might commonly view those who use sentences to search as lacking higher-order thinking abilities, since they did not demonstrate an ability to deconstruct ideas into representative search terms. Such a presumption was negated by the finding that students who used sentences to search also earned high scores on their projects. Probably it is the individual phrases within the sentences that help search engines narrow down the information in question, effectively decreasing the cognitive load that a mix of relevant and less relevant information would generate for information seekers. Recent advances in search engines with regards to mapping search results with several search terms likely have lessened the need for exactitude in the selection of search term (Jansen, Spink, \& Saracevic, 2000). Both of the topics related to the patterns between multiple search terms or within phrases, as well as information relevancy with regards to sentences, would be worth further investigation.

Completing an IPS task to a high level of quality requires not only the engagement of relevant information search and organisation strategies, but also the metacognitive ability to coordinate these strategies in harmony with one another. With long-term endeavours defining implicit information search behaviours (Liang \& Tsai, 2009; Tsai \& Tsai, 2003), Tsai and colleagues found a limited correlation between evaluation and other explicit strategies, which implied an independent relationship between implicit and explicit strategies when they further analysed information seekers' explicit and implicit strategy utilisation (Tsai, et al., 2012). By further analysing those students with different search proficiencies, we found thresholds within and between the implicit and explicit strategies. Information problem solvers with good IPS strategies tended to have better implicit strategies and higher project scores, while those with basic or intermediate ones did not show their implicit strategies to be at equivalent levels (might be over-rating or underrating). In that way, we assumed that the lack of good self-monitoring abilities probably hindered their search behaviours and results. Similar to the concept that regulation-related activities (e.g. orientation, monitoring, steering, and evaluating) are necessary to IPS (Brand-Gruwel et al., 2005, 2009), the findings of this study suggest that self-regulatory abilities are as critical as the IPS strategies identified within the process of information seeking or IPS. Compared to the ample findings regarding the procedural strategies, more studies focusing on regulatory strategies would be informative regarding students' IPS behaviours.

The designs of the IPS course and OIM interface were another focus of this study. In order to develop students' science literacy, the "benchmarks" (American Association for the Advancement of Science, 1993, 2009) indicate that middle school students should acquire problem solving abilities geared toward the use of appropriate technological tools to investigate scientific issues and solve practical problems. In that way, electronic resources not only offer students information for the target problems, but also develop their higher-order thinking abilities when encountering data from different sources. Since the development of IPS abilities is individualised and varies with information seeker's experiences, background knowledge, and (meta-) cognitive strategies, students' search profiles that included both the information being copied and dragged and the reflective notes and highlights the students left in our interface communicated these students' logical thinking processes. Such information processing records not only helped these students shift their attention to information management (rather than information collection), but also better informed teachers regarding how to help these students polish their information presentations. 


\section{Conclusion and implications}

Through careful examination of 28 students' information organisation processes and projects, this study identified the strategies that expert and novice information seekers use to solve information problems. Compared to those with higher project scores possessing good explicit and implicit strategies, the students with intermediate or lower project scores were found to lack sufficient self-monitoring abilities which may discourage these students from further refining their IPS strategies and prevent their teachers from making accurate evaluations and providing effective lectures. For such students, teachers should focus on enhancing self-monitoring abilities. After all, without good self-monitoring abilities, students may easily feel overwhelmed by the abundance of online information or allow themselves to be satisfied only with general information retrieved without organisation. Moreover, the formatting of search terms in Boolean operators is not as critical as it once used to be. The keywords being entered should not only be relevant to the intended topic but also be of an adequate quantity to identify and retrieve the necessary information. Embedded within the development of inquiry abilities and information search strategies, the IPS curricula that provide students with individualised and meaningful learning experiences, and empower students with strategies for surviving in a digital world, will be excellent class activities for all subject areas.

\section{Acknowledgements}

This research was funded by “Aim for the Top University Project” at National Taiwan Normal University.

\section{References}

Ackerman, E., \& Karen H. (2005). Searching and researching on the Internet and the world wide web (4rd ed.). Wilsonville, OR: Franklin Beedle \& Associates.

American Association for the Advancement of Science [AAAS]. (1993, 2009). Benchmarks for science literacy. New York, NY: Oxford University Press. Retrieved from http://www.project2061.org/publications/bsl/online/index.php

Becker, H. J. (1999). Internet use by teachers: Conditions of professional use and teacher-directed student use (Report \#1). Irvine, CA: Center for Research on Information Technology and Organizations, University of California, Irvine, and the University of Minnesota. Retrieved December 15, 2012 from http://www.crito.uci.edu/tlc/findings/internet-use/text-tables.pdf [viewed 15 Dec. 2012].

Belkin, N. J. (2000). Helping people find what they don't know. Communications of the ACM, 43, 58-61.

Bell, P., Davis, E. A., \& Linn, M. C. (1995). The knowledge integration environment: Theory and design. In J. L. Schnase \& E. L. Cunnius (Eds.), Proceedings of Computer Support for Collaborative Learning '95 (pp. 14-21). Mahwah, NJ: Lawrence Erlbaum Associates.

Brand-Gruwel, S., Wopereis, I., \& Vermetten, Y. (2005). Information problem solving by experts and novices: Analysis of a complex cognitive skill. Computers in Human Behavior, 21, 487-508.

Brand-Gruwel, S., Wopereis, I., \& Walraven, A. (2009). A descriptive model of information problem solving while using internet. Computers \& Education, 53, 1207-1217.

Butcher, K., \& Sumner, T. (2011). How does prior knowledge impact students' online learning behaviors? International Journal of Cyber Behavior, Psychology and Learning (IJCBPL), 1(4), 1-18.

Chen, S.-Y., Fan, J.-P., \& Macredie, R. D. (2006). Navigation in hypermedia learning system: experts vs. novices. Computers in Human Behavior, 22(2), 251-266.

De Vries, B., van der Meij, H., \& Lazonder, A. W. (2008). Supporting reflective web searching in elementary schools. Computers in Human Behavior, 24(3), 649-665. 
Eisenberg, M. B., \& Berkowitz, R. E. (1990). Information-problem solving: The big six skills approach to library and information skills instruction. Norwood, NJ: Ablex.

Eisenberg., M. B., \& Berkowitz, R. E. (1992). Information problem-solving: The big six skills approach. School Liberty Media Activities Monthly, 8(5), 27-29.

Eisenberg, M. B., Berkowitz, R., Darrow, R., \& Spitzer, K. (2000). Teaching information and technology skills: The Big6 in secondary schools. Columbus, OH: Linworth Publishing.

Ellis, D. (1989). A behavioral approach to information retrieval design. Journal of Documentation, 45 , 171-212.

Ellis, D. (1993). Modeling the information seeking patterns of academic researchers: A grounded theory approach. Library Quarterly, 63, 469-486.

Foster, A. (2005). A nonlinear model of information-seeking behavior. Journal of the American Society for Information Science and Technology, 55, 228-237.

Gagne, E. D., Yekovich, C. W., \& Yekovich, F. R. (1993). The cognitive psychology of school learning (2nd ed.). NY: Harper Collins.

Gerjets, P., Kammerer, Y., \& Werner, B. (2011). Measuring spontaneous and instructed evaluation processes during web search: Integrating concurrent thinking-aloud protocols and eye-tracking data. Learning and Instruction, 21, 220-231.

Hill, J. R. (1999). A conceptual framework for understanding information seeking in open-ended information services. Educational Technology, Research and Development, 47(1), 5-27.

Hill, J. R., \& Hannafin, M. J. (1997). Cognitive strategies and learning from the world wide web. Educational Technology Research and Development, 45, 37-64.

Hsie-Yee, I. (2001). Research on Web search behavior. Library \& Information Science, 23, 167-185.

Hwang, G.-J., Tsai, P.-S., Tsai, C.-C., \& Tseng, J. C. R. (2008). A novel approach for assisting teachers in analyzing student web-searching behaviors. Computers \& Education, 51, 926-938.

Jansen, B. J., \& Pooch, U. (2001). A review of Web searching studies and a framework for future research. Journal of the American Society for Information Science and Technology, 52, 235-246.

Jansen, B. J., Spink, A. H., \& Saracevic, T. (2000). Real life, real users, and real needs: a study and analysis of user queries on the web. Information Processing and Management, 36(2), pp. 207-227.

Jenkins, C., Corritore, C. L., \& Wiedenbeck, S. (2003). Patterns of information seeking on the web: A qualitative study of domain expertise and web expertise. IT \& Society, 1(3), 64-89.

Jones, B. D. (2002). Recommendations for implementing Internet inquiry projects. Journal of Educational Technology Systems,30(3), 271-291.

Kim, M. C., Hannafin, M. J., \& Bryan, L. A. (2007). Technology-enhanced inquiry tools in science education: An emerging pedagogical framework for classroom practice. Science Education, 91, 1010 1030.

Kuhlthau, C. C. (1993). A principle of uncertainty for information seeking. Journal of Documentation, 49, 339-355.

Kuiper, E., Volman, M., \& Terwel, J. (2008). Students' use of web literacy skills and strategies: Searching, reading and evaluating web information. Information Research, 13(3), 5.

Lazonder, A. \& Rouet, J.F. (2008). Information problem solving instruction: Some cognitive and metacognitive issues. Computers in Human Behavior, 24(3), 753-765. 
Levin, J. A., \& Kauwell, D. A. (1999, April). Visualization of web-based information and sense making. In F. R. Rusch, Technology-based tools for learning: analysis and synthesis in the $21^{\text {st }}$ century. Symposium conducted at the annual meeting of the American Educational Research Association. Montreal, Quebec.

Liang, J.-C., \& Tsai, C.-C. (2009). The information commitments toward web information among medical students in Taiwan. Educational Technology \& Society, 12, 162-172.

Liaw, S.-S., \& Huang, H.-M. (2006). Information retrieval from the World Wide Web: a user-focused approach based on individual with search engines. Computers in Human Behavior, 22, 501-517.

Mahoui, M., \& Cunningham, S. J. (2000). A comparative transaction log analysis of two computing collections. In Borbinha, J. \& Baker, T. (Eds.): ECDL 2000, 418-423.

Marchionini, G. (1995). Information seeking in electronic environments. New York: Cambridge University Press.

Mason, L., Ariasi, N., \& Boldrin, A. (2011). Epistemic beliefs in action: Spontaneous reflections about knowledge and knowing during online information searching and their influence on learning. Learning and Instruction, 21(1), 137-151.

Mokhtari, K., Kymes, A., \& Edwards, P. (2009). Assessing the new literacies of online reading comprehension: An informative interview with W. Ian O'Byrne, Lisa Zawilinski, J. Greg McVerry, and Donald J. Leu at the University of Connecticut. The Reading Teacher, 62(4), 354-357.

Navarro-Prieto, R., Scaife, M., \& Rogers, Y. (1999). Cognitive strategies in web searching. Proceedings from the 5th Conference on Human Factors and the Web. http://disi.unitn.it/ agostini/WIR06/data/DBstudents/Paper18.pdf

Nielson, J. (1994). Multimedia and hypertext: The internet and beyond. Boston: Academic press. Qiu, L. (1993). Markov models of search state patterns in a hypertext information retrieval system. Journal of the American Society for Information Science, 44, 413-427.

Raban, D. R. (2007). User-centered evaluation of information: a research challenge. Internet Research, 17, $306-322$.

Rose, M., Rose, G., M., \& Blodgett, J. G. (2009). The effects of internet design and age on children's information processing of web sites. Psychology \& Marketing, 26(1). 1-21.

Schraw, G. (1998). Promoting general metacognitive awareness. Instructional Science, 26, 113-125.

Sharit, J., Hernández, M. A., Czaja, S. J., \& Pirolli, P. (2008). Investigating the roles of knowledge and cognitive abilities in older adult information seeking on the web. ACM Transactions on ComputerHuman Interaction (TOCHI), 15(1), 3.

Stone, A. (1998) The metaphor of scaffolding: Its utility for the field of learning disabilities. Journal of Learning Disabilities, 31(4), 344-364.

Tabatabai, D., \& Shore, B. M. (2005). How experts and novices search the Web. Library and Information Science Research, 27, 222-248.

Tauscher, L., \& Greenberg, S. (1997). How people revisit Web pages: empirical findings and implications for the design of history systems. International Journal of Human-Computer Studies, 47, 97-137.

Thatcher, A. (2006). Information-seeking behaviours and cognitive search strategies in different search tasks on the WWW. International Journal of Industrial Ergonomics, 36(12), 1055-1068.

Thatcher, A. (2008). Web searching strategies: The influence of Web experience and task type. Information Processing and Management, 44(3), 1308-1329. 
Tsai, M.-J., Hsu, C.-H., \& Tsai, C.-C. (2012). Investigating of high school students' online science information searching performance: The role of implicit and explicit strategies. Journal of Science and Educational Technology, 21, 246-254.

Tsai, M.-J., \& Tsai, C.-C. (2003). Information searching strategies in web-based science learning: The role of Internet self-efficacy. Innovations in Education and Teaching International, 40(1), 3-5.

Vakkari, P. (1999). Task complexity, problem structure and information actions: Integrating studies on information seeking and retrieval. Information Processing \&Management, 35(6), 819-837.

Wallace, R. (1997). On-line information seeking in a sixth grade classroom. Unpublished manuscript. University of Michigan, Ann Arbor.

Wallace, R. MC., Kupperman, J., Krajcik, J., \& Soloway, E. (2000). Science on the web: Students online in a sixth-grade classroom. The Journal of The Learning Sciences, 9(1), 75-104.

Walraven, A., Brand-Gruwel, S., \& Boshuizen, H. P. A. (2008). Information problem solving: A review of problems students encounter and instructional solutions. Computers in Human Behaviors, 24, 623 648.

Walraven, A., Brand-Gruwel, S., \& Boshuizen, H. (2009). How students evaluate information and sources when searching the World Wide Web for information. Computers \& Education, 52(1), 234246.

Walraven, A., Brand-Gruwel, S., \& Boshuizen, H. (2010). Fostering transfer of websearchers' evaluation skills: A field test of two transfer theories. Computers in Human Behavior, 26(4), 716-728.

Walraven, A., Brand-Gruwel, S., \& Boshuizen, H. (2013). Fostering students' evaluation behaviour while searching the internet. Instructional Science, 41(1), 125-146.

Winne, P., \& Hadwin, A. (2013). nStudy: Tracing and supporting self-regulated learning in the Internet. In International handbook of metacognition and Learning technologies (pp. 293-308). Springer New York.

Corresponding author: Ying-Shao Hsu, yshsu@ntnu.edu.tw

Australasian Journal of Educational Technology (C) 2014.

Please cite as: Yeh, Y.-F, Hsu, Y.-S., Chuang, F.-T., \& Hwang, F.-K. (2013). Middle-school students' online-information management behaviors on the information retrieval interface. Australasian Journal of Educational Technology, 30(2), 245-260. 